\title{
Jean Thenaud, Le triumphe des vertuz. Quatrième traité: Le triumphe de temperance
}

\section{Michele Mastroianni}

\section{(2) OpenEdition}

1 Journals

\section{Edizione digitale}

URL: http://journals.openedition.org/studifrancesi/5893

DOI: 10.4000/studifrancesi.5893

ISSN: 2421-5856

\section{Editore}

Rosenberg \& Sellier

\section{Edizione cartacea}

Data di pubblicazione: 1 mai 2011

Paginazione: 155-156

ISSN: 0039-2944

\section{Notizia bibliografica digitale}

Michele Mastroianni, «Jean Thenaud, Le triumphe des vertuz. Quatrième traité: Le triumphe de

temperance», Studi Francesi [Online], 163 (LV | I) | 2011, online dal 30 novembre 2015, consultato il 08 janvier 2021. URL: http://journals.openedition.org/studifrancesi/5893 ; DOI: https://doi.org/10.4000/ studifrancesi.5893

Questo documento è stato generato automaticamente il 8 janvier 2021.

\section{(c) $($ ) $\odot$}

Studi Francesi è distribuita con Licenza Creative Commons Attribuzione - Non commerciale - Non opere derivate 4.0 Internazionale. 


\title{
Jean Thenaud, Le triumphe des vertuz. Quatrième traité: Le triumphe de
}

\section{temperance}

\author{
Michele Mastroianni
}

\section{NOTIZIA}

JEAN THENAUD, Le triumphe des vertuz. Quatrième traité: Le triumphe de temperance, édition critique par Titia J. SCHUURS-JANSSEN et René E.V. STUIP, Genève, Droz («Textes Littéraires Français», 601), 2010, pp. LXXIX-475.

1 Con la pubblicazione del Triumphe de Temperance si conclude l'edizione critica del Triumphe des Vertuz di Jean Thenaud (Triumphe de Prudence, TLF 489, 1997; Triumphe de Force, TLF 550, 2002; Triumphe de Justice, TLF 589, 2007), opera veramente monumentale che, pur avendo avuto circolazione e goduto di prestigio alla corte di Francia, era rimasta allo stato di manoscritto. Composto su commande di Luisa di Savoia per i suoi due figli, la futura Marguerite de Navarre e François I, questo miroir des princes, terminato intorno agli anni 1517-1518, pur riprendendo un genere medievale attinge ispirazione da testi decisamente umanistici oppure patristici e medievali ricorrenti nell'Umanesimo: gli editori segnalano in particolare Erasmo, san Gerolamo, Giovanni di Salisbury, Agrippa von Nettesheim, Francesco Colonna e Jean Tixier de Ravisy (Joannes Ravisius Textor). Nell'introduzione, queste ascendenze sono illustrate: particolarmente interessanti sono i riferimenti alla Querela pacis erasmiana e all'Hypnerotomachia di Francesco Colonna in quanto dimostrano l'apertura di Thenaud a testi moderni e nuovi. Così pure la presenza di Ravisius Textor, se da un lato segnala il persistere del gusto per l'enciclopedismo, dall'altro è pur sempre segno di condivisione di interessi umanistici, senza contare che l'opera di Tixier e quella di Thenaud denunciano fonti comuni interpretate alla luce di interessi differenti. Oltre all'importantissima questione delle fonti, l'introduzione affronta i seguenti problemi: la struttura generale dell'opera (un manuale pedagogico, destinato alle giovani donne nobili che, sulla scia della regina 
Claude, protagonista del trattato, perseguono la virtù della temperanza); le motivazioni per cui un trattato 'al femminile' dà grande rilievo ai tornei e agli scontri cavallereschi; il vocabolario e la morfologia del trattato. Un dizionario tematico facilita la lettura di questo testo enciclopedico. Annotazioni e glossario sono accurati; esauriente è la bibliografia. 